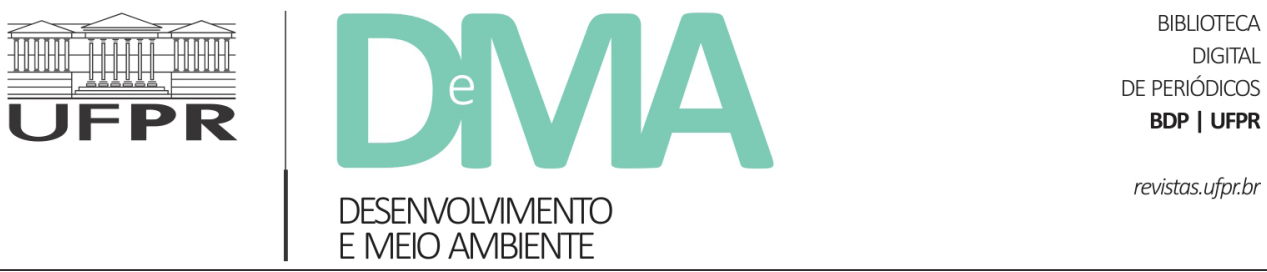

\title{
Avaliação do consumo energético e emissões de dióxido de carbono do transporte rodoviário do Brasil (2016-2026)
}

\section{Evaluation of energy consumption and emissions of carbon dioxide of road transport of Brazil (2016-2026)}

\author{
Olivia Nascimento Boldrini NICOLAU ${ }^{1 *}$, Gisele de Lorena Diniz CHAVES ${ }^{1}$, Igor Tureta ZANCHETTA ${ }^{1}$ \\ ${ }^{1}$ Universidade Federal do Espírito Santo (UFES), Vitória, ES, Brasil. \\ *E-mail de contato: olivianboldrini@gmail.com
}

Artigo recebido em 31 de outubro de 2018, versão final aceita em 22 de abril de 2020, publicado em 5 de outubro de 2020.

RESUMO: O setor de transporte é um setor-chave para o desenvolvimento de um país, mas demanda muita energia oriunda de combustíveis fósseis, gerando volumes consideráveis de gases do efeito estufa. Dada a importância do setor e seu potencial poluidor, este trabalho busca avaliar o consumo energético e a emissão de $\mathrm{CO}_{2}$ do modal rodoviário no Brasil. Para isso, o método System Dynamics (SD) foi escolhido, envolvendo as relações entre frota de veículos, PIB (global e do setor de transporte) e investimentos em infraestrutura rodoviária (extensão de vias). Com o modelo proposto, nove cenários foram simulados em um horizonte de onze anos, compreendidos entre 2016 e 2026, sob diferentes perspectivas. Os resultados evidenciaram que a variação da frota de veículos rodoviários tem maior influência no consumo energético e, consequentemente, nas emissões de $\mathrm{CO}_{2}$, quando comparado com a composição de uso de combustíveis e investimentos em pavimentações de vias.

Palavras-chave: emissão de $\mathrm{CO}_{2}$; setor de transporte; modal rodoviário.

ABSTRACT: The transport sector is a key sector for the development of a country, but it demands significant energy from fossil fuels generating considerable amounts of greenhouse gases. Given the importance of this sector and its polluting potential, this paper seeks to evaluate the energy consumption and the $\mathrm{CO}_{2}$ emission from road transport in Brazil. For this, the System Dynamics (SD) method was chosen, involving the relationships between vehicle fleet, GDP (global and transport sector) and investments in road infrastructure (road extension). With the proposed model, nine scenarios were simulated over eleven- years, between 2016 and 2026, from different perspectives. The results showed that the variation of the road vehicle fleet has a 
greater influence on the energy consumption and consequently, on the $\mathrm{CO}_{2}$ missions when compared to the composition of fuel use and investments in road pavements.

Keywords: $\mathrm{CO}_{2}$ emission; transportation sector; road mode.

\section{Introdução}

O setor de transporte é chave para o desenvolvimento de um país, uma vez que dá suporte para o desenvolvimento econômico e social de uma nação, possibilitando a alocação eficiente de materiais e recursos, além de proporcionar mobilidade para a população. Saboori et al. (2014) afirmam que o alto nível de crescimento econômico, a rápida urbanização, o aumento da renda disponível, a diversificação das atividades sociais e de lazer, o rápido crescimento do número de veículos particulares e a distribuição desigual de materiais e recursos energéticos aumentam a demanda por transporte. Contudo, esse aumento da demanda traz consigo o aumento do impacto ambiental decorrente das atividades desse setor. $\mathrm{O}$ crescimento nos índices de emissão de gases do efeito estufa (GEE) proveniente do setor de transportes e sua participação nas emissões de dióxido de carbono $\left(\mathrm{CO}_{2}\right)$ está aumentando gradualmente em todas as regiões do mundo.

No período de 1990 a 2015, as emissões totais de $\mathrm{CO}_{2}$ tiveram um crescimento de $13 \%$ de acordo com a Agência Internacional de Energia (IEA, 2015). Em contrapartida, as emissões de $\mathrm{CO}_{2}$ provenientes do setor de transporte tiveram um aumento de $68 \%$ no mesmo período. No ano de 2015 , o setor de transporte respondeu por $24 \%$ das emissões totais de $\mathrm{CO}_{2}$, sendo três quartos dessa emissão decorrente de atividades do modal rodoviário (IEA, 2015). No caso do Brasil, de 2007 a 2014, foi observado um significativo crescimento na utilização energética do setor, com maior crescimento em 2010: 10,9\% em relação ao ano anterior. Nos anos de 2015 e 2016, houve um decréscimo de $2,10 \%$ e $1,06 \%$, respectivamente, no uso de energia pelo setor em função da crise econômica vivenciada no país (EPE, 2017).

Em termos de emissão de $\mathrm{CO}_{2}$, o setor de transporte no Brasil acompanha o cenário mundial. Em 2016, o setor foi responsável por $29 \%$ das emissões de $\mathrm{CO}_{2}$ no Brasil. Desse percentual, $90 \%$ é relativo ao modal rodoviário (Observatório do clima, 2017), sendo considerado o setor que mais impacta na qualidade do ar no país.

No Brasil, o modal rodoviário responde por $60 \%$ do transporte de passageiros e cargas, em contraste com $21 \%$ na China e 39\% na Índia (Raiser et al., 2017). Por esse motivo, esse modal merece maior atenção no que diz respeito a suas atividades e impactos. Desta forma, este trabalho tem como finalidade propor um modelo para demonstrar como o crescimento econômico, extensão de vias pavimentadas e a frota de veículos impactam as emissões de $\mathrm{CO}_{2}$ e o consumo energético do setor de transporte no Brasil. Para isso, uma simulação utilizando o método de Dinâmica de Sistemas foi proposta. Abbas \& Bell (1994) e Shepherd (2014) explicam que a dinâmica de sistemas permite que sistemas de grande escala, tais como sistemas de transporte, podem ser facilmente modelados, analisados e testados. 


\section{A relação entre PIB, infraestrutura, frota de veículos, emissões de $\mathrm{CO}_{2}$ e consumo energético}

O desenvolvimento econômico está intimamente relacionado ao consumo de energia, uma vez que mais consumo de energia leva a um maior desenvolvimento econômico por meio do aumento da produtividade. No entanto, também é igualmente provável que o uso mais eficiente da energia, que poderia resultar em uma redução no consumo energético, possa exigir um nível mais alto de desenvolvimento econômico. Ou seja, um melhor desempenho econômico pode ser um catalisador para a eficiência energética (Ang, 2007).

Preocupações crescentes sobre o meio ambiente despertaram a atenção dos formuladores de políticas, para identificar os determinantes das poluições ambientais e a direção de sua influência (Ghosh, 2010; Wang et al., 2011). Entre as variáveis mais importantes associadas à degradação ambiental estão o consumo de energia e os objetivos de desenvolvimento econômico que um país persegue em detrimento do meio ambiente. Embora isso tenha se traduzido na identificação dos determinantes das poluições ambientais, a maioria dos estudos limitaram sua análise apenas ligando o consumo total de energia e o crescimento econômico à poluição ambiental, particularmente as emissões de $\mathrm{CO}_{2}$. Só o consumo de energia e o crescimento podem não explicar as emissões de $\mathrm{CO}_{2}$ (Ozturk \& Acaravci, 2013). Devido ao crescimento econômico e combustão de combustíveis fósseis, as emissões de poluentes aumentaram progressivamente, exigindo atenção urgente de estudiosos e formuladores de políticas para identificar suas fontes além do escopo do uso total de energia (Lean \& Smyth, 2010).
Fodha \& Zaghdoud (2010) investigaram a relação entre o crescimento econômico e as emissões de $\mathrm{CO}_{2}$ para a Tunísia no período de 1961 a 2004. Os resultados da causalidade mostraram que existe uma relação unidirecional que vai do crescimento econômico à poluição, tanto no curto como no longo prazo. No caso da África do Sul, Menyah \& Wolde-Rufael (2010) examinaram a relação entre crescimento econômico, emissões de $\mathrm{CO}_{2} \mathrm{e}$ consumo de energia para o período 1965-2006. O resultado do teste de causalidade de Granger mostrou uma relação unidirecional entre as emissões de $\mathrm{CO}_{2}$ e o PIB; do consumo de energia ao PIB e do consumo de energia às emissões de $\mathrm{CO}_{2}$.

Em uma análise empírica, Halicioglu (2009) investigou a relação causal entre as emissões de $\mathrm{CO}_{2}$ e o crescimento econômico da Turquia empregando uma abordagem de análise da cointegração entre as variáveis e modelos autorregressivos de defasagens distribuídas (ARDL) no período de 1960-2005. Suas descobertas confirmaram a hipótese de feedback tanto no curto como no longo prazo. Usando a abordagem de teste de limites ARDL complementada por Johansen-Juselius, Ghosh (2010) mostrou que existe uma causalidade de curto prazo bidirecional entre as emissões de $\mathrm{CO}_{2}$ e o crescimento econômico na Índia durante 1971-2006. Wang et al. (2011) usaram o modelo de correção de erros para verificar a relação causal entre as emissões de $\mathrm{CO}_{2}$ e o crescimento econômico de 138 países durante o período de 1971 a 2007, e encontram evidências para apoiar a hipótese de feedback.

Alguns estudos, como Pao \& Tsai (2010), examinaram relações causais dinâmicas entre emissões de poluentes, consumo de energia e produção para um painel de países do BRIC (grupo de países emergentes formado por Brasil, Rússia, Índia e China) 
durante o período de 1971 a 2005. Os resultados de causalidade do painel indicaram que há relação forte de causalidade bidirecional entre consumo de energia e emissões, porém o estudo não fornece uma visão sistêmica do problema.

Os mesmos autores, utilizando o método de causalidade multivariável de Granger, abordaram o impacto do crescimento econômico e do desenvolvimento financeiro na degradação ambiental, usando uma técnica de cointegração de painel para o período entre 1980 e 2007 para países pertencentes ao BRIC. Os resultados mostraram que esses países são dependentes de energia, assim, devem adotar métodos de gerenciar tanto a demanda de energia quanto o investimento estrangeiro direto e aumentar o investimento no fornecimento de energia e eficiência energética para reduzir as emissões de $\mathrm{CO}_{2}$, sem comprometer a competitividade (Pao \& Tsai, 2011).

Hossain (2011) examinou empiricamente as relações causais entre as emissões de dióxido de carbono, consumo de energia, crescimento econômico, abertura comercial e urbanização para o painel de países recentemente industrializados, entre eles, o Brasil. Como resultado, verificou-se que não há evidência de relação causal de longo prazo, mas há relação causal unidirecional de curto prazo do crescimento econômico e abertura comercial às emissões de dióxido de carbono, do crescimento econômico ao consumo de energia, da abertura comercial ao crescimento econômico, da urbanização ao crescimento econômico e da abertura comercial à urbanização.

Azlina et al. (2014) utilizaram a dinâmica de sistemas para criar um modelo que identifica a relação entre renda, consumo de energia e emissão de $\mathrm{CO}_{2}$ na Malásia no período de 1975 a 2011. Os resultados obtidos pelos autores mostraram que há uma relação causal em longo prazo entre as três variáveis abordadas. Os resultados foram comparados com alguns métodos econométricos que avaliam as relações causais, como a curva de Kuznet, para validar o método de dinâmica de sistemas. Amann et al. (2016) investigaram a relação entre crescimento e gastos em infraestrutura no contexto brasileiro e a natureza e causas do subinvestimento em infraestrutura com foco no setor de transporte urbano. Nesse estudo, chegaram à conclusão de que uma razão central para o déficit de infraestrutura existente está associada a problemas com o projeto e implementação regulatória.

Conforme exposto, no caso do Brasil não há estudos que analisam de forma sistêmica todas as inter-relações existentes entre os fatores citados e como eles se comportam em diferentes cenários ao longo do tempo. Todos os estudos apresentados buscaram identificar as relações diretas entre esses fatores, por meio de métodos estatísticos que não avaliam o comportamento dinâmico das variáveis. Dessa forma, o próposito desse estudo é preencher essa lacuna existente na literatura.

\section{Modelagem pela dinâmica de sistemas}

A dinâmica de sistemas é usada para o entendimento de sistemas complexos cujas variáveis interajam entre si. Em outras palavras, as variáveis não são definidas como um conceito direto de variável dependente e independente. Ao contrário de outras formas de simulação, as quais tem-se variáveis dependentes ou independentes, na dinâmica de sistema as variáveis interagem constantemente entre si. Em pesquisas de cunho acadêmico, essa metodologia vem sendo utilizada para a modelagem 
de ambientes de negócios, de cadeias de produção e suprimentos e de sistemas sociais complexos, onde há interatividade constante dos seus agentes (Richardson, 1996; Sterman, 2000).

A simulação por dinâmica de sistemas (DS) caracteriza-se pela análise das características de respostas sobre decisões tomadas em sistemas sociais para demonstrar como estruturas organizacionais e atrasos interagem influenciando no comportamento desses sistemas. As aplicações desta abordagem variam desde a cadeia de suprimentos até sistemas urbanos, econômicos e ecossistemas. Os modelos de dinâmica de sistemas são representados por níveis, fluxos entre estes níveis e informações que determinam a magnitude destes fluxos. Nesta abordagem as entidades e eventos singulares são abstraídos e agregados em políticas e variáveis globais. As variáveis, ao contrário do que ocorre na simulação de eventos discretos, são consideradas contínuas, o que, em muitos casos, como no de fluxo de materiais na cadeia de suprimentos, é uma aproximação da realidade. Porém, ela é válida devido ao nível de agregação que se utiliza nos problemas estudados, não prejudicando as observações (Sterman, 2000).

A fase qualitativa tem início com a identificação do sistema, seu alcance e interfaces, ou seja, limita-se o sistema e o objetivo do estudo, bem como as variáveis de entrada e saída do modelo. A partir de então, o modelo conceitual é construído por meio do Diagrama de Causa e Efeito (DCE), o qual ilustra a relação causal entre as variáveis identificadas, auxiliando como rascunho preliminar de hipóteses causais e simplificando a representação do modelo (Naim \& Towill, 1994; Georgiadis \& Vlachos, 2004).

Os elementos básicos de um DCE são variáveis relacionadas por meio de setas de sinal negativo ou positivo, representando uma relação causal. Uma relação positiva, ou diretamente proporcional significa que, se a causa aumentar, o efeito aumenta, ou, se a causa diminuir, o efeito diminui. Uma relação negativa, ou inversamente proporcional, significa que, se a causa aumentar, o efeito diminui; se a causa diminuir, o efeito aumenta (Sterman, 2000).

Além das variáveis relacionadas por meio de setas, esses diagramas são caracterizados por laços de realimentação de polaridade positiva ou negativa, representados por ciclos no sentido horário ou anti-horário com sinais (+) ou (-) (Forrester, 1985). Um laço de realimentação é uma sucessão de causas e efeitos tais que uma mudança em uma dada variável repercute através do laço e torna a afetar a mesma variável (Morecroft, 2015). Segundo Georgiadis \& Vlachos (2004), se um aumento na variável inicial provoca, através do laço, um aumento final na mesma variável, então o laço de realimentação é considerado positivo. Ao contrário, se um aumento em uma dada variável inicial afeta o laço de modo a diminuir o valor dessa mesma variável, então o laço de realimentação é identificado como negativo. De acordo com Sterman (2000), esse método de determinação da polaridade do laço funciona independentemente da quantidade de variáveis existentes no laço e de qual seja a variável inicial do efeito, levando ao mesmo resultado.

No entanto, os diagramas de causa e efeito não diferenciam as acumulações dos recursos e as taxas de mudança dos recursos em um sistema, ou seja, estoques e fluxos (Sterman, 2000). Por isso, utiliza-se uma forma mais completa de representação dos sistemas, os Diagramas de Estoque e Fluxo (DEF), construídos com basicamente quatro componentes: estoques, fluxos, auxiliares e conectores. 
Os Diagramas de Estoque e Fluxo são baseados na matemática diferencial e na construção de sistemas de equações diferenciais. Os sistemas de equações - que são resolvidas por softwares - são compostos por variáveis que representam a acumulação no sistema (denominados estoques), os fluxos (que alimentam e vazam os estoques) e variáveis auxiliares. Em termos matemáticos, o estoque representa a resolução de uma equação diferencial dentro do sistema de equações (Sterman, 2000).

\section{A relação causal do problema estudado}

Existe uma ligação clara entre crescimento econômico e transporte (Ong et al., 2012). Gwilliam (2003) explica que o processo de crescimento implica em uma crescente demanda de transporte para que seja possível acessar os diferentes mercados. Dessa forma, a debilidade do setor de transporte limita o desenvolvimento. Não somente porque as condições ruins de transporte mitigam as alternativas de ganhos através do comércio, mas também porque uma infraestrutura ruim afeta negativamente a produtividade de outros setores.

Nesse cenário, o desenvolvimento da infraestrutura afeta o crescimento econômico de diversas maneiras. $\mathrm{O}$ aumento nos investimentos em infraestrutura de transporte em uma região provoca uma redução nos custos dos insumos industriais no processo de produção. Esta redução deve-se às melhorias no fluxo de transporte que, consequentemente, promove maior circulação de capital na região, inferindo em crescimento da economia local (Snieska \& Simkunaite, 2009).

Outro fator que está ligado diretamente ao aumento dos níveis de investimentos em infraes- trutura de transporte é o nível de atratividade da região (Banister \& Berechman, 2001). Segundo Diaz et al. (2016), o investimento em infraestrutura de transporte em uma região promove um aumento na responsividade e flexibilidade na entrega de bens e serviços, o que potencialmente aumenta a atratividade local. Consequentemente, mais empresas são instaladas na região, o que gera novos empregos para a cidade e municípios próximos, elevando assim a economia da região. $\mathrm{O}$ aumento do investimento em infraestrutura também promove um maior fluxo de veículos na região, o que promove maior emissão de $\mathrm{CO}_{2}$, por consequência (Chandran \& Tang, 2013).

A emissão de $\mathrm{CO}_{2}$ apresenta uma relação inversamente proporcional ao crescimento econômico, ou seja, quanto maior a emissão de $\mathrm{CO}_{2}$, menor será o crescimento econômico em longo prazo, devido ao aumento da poluição e emissão de gases causadores do efeito estufa, tornando o local menos atrativo para receber investimentos (Chandran \& Tang, 2013). Vershinina et al. (2015) explicam que os indicadores ambientais são muito importantes do ponto de vista de um investidor estrangeiro que pretende investir diretamente na economia de uma região, porque nos países desenvolvidos, a legislação ambiental é bastante rígida, e sua não conformidade implica em sanções financeiras e administrativas significativas. Portanto, a avaliação global das despesas de manutenção do ambiente natural é uma medida importante no quadro geral de indicadores de atratividade do investimento da economia de certo local. Sari \& Soytas (2009) reforçam a ideia, explicando que o aumento nos níveis de emissões contribui para os danos decorrentes do efeito estufa e podem provocar escassez de água e processo de desertificação em algumas nações, o que impactaria negativamente no desempenho econômico de uma 
nação. Assim, Coondoo \& Dinda (2002) em seu trabalho sugerem que os países desenvolvidos e em desenvolvimento devem sacrificar o crescimento econômico para reduzir os níveis de emissão.

$\mathrm{O}$ crescimento econômico também possui relação direta com o consumo energético. Vários estudos dedicam-se à compreensão dessa relação. Stern (1993) analisou os efeitos do uso de energia sobre o crescimento econômico e concluiu que o uso da energia pode ser limitador para o crescimento do produto interno de um país. Chontanawat et al. (2008) também concluíram que existe a relação proporcional entre esses dois fatores, tanto do consumo de energia para o crescimento do produto quanto o efeito redutor que políticas restritivas para utilização energética, com o objetivo de conter a emissão de gases do efeito estufa, teriam sobre o crescimento da economia. Ghali \& El-Sakka (2004) também corroboraram com essa relação, demonstrando em seu estudo que existe um fluxo bidirecional entre o PIB e o consumo de energia, concluindo também que a energia pode ser um fator limitante para o incremento do produto. Narayan \& Smith (2008) chegaram à conclusão de que a redução do consumo energético teria efeito negativo sobre a atividade produtiva dos países pertencentes ao G7, e a implantação de medidas que focassem em prevenção ambiental deveriam considerar alternativas para minimizar os seus efeitos sobre o crescimento econômico.

A relação bidirecional entre crescimento econômico e investimento em infraestrutura de transporte é determinante para o modelo, pois é a única relação que apresenta um comportamento de crescimento exponencial (ciclo positivo) ao sistema. Os demais feedbacks do modelo são de caráter negativo, cujo objetivo é de balancear o sistema.
Ao aumentar o crescimento econômico, há um aumento nas vendas de veículos (frota de veículos), o que ocasiona uma maior emissão de $\mathrm{CO}_{2}$, devido ao aumento de atividades de transporte e, consequentemente, há um aumento no consumo de energia (Ong et al., 2012). Contudo, a emissão de $\mathrm{CO}_{2}$ apresenta uma relação inversamente proporcional ao crescimento econômico, ou seja, ao aumentar a poluição local, a região se torna menos atrativa, diminuindo assim o crescimento econômico (Chandran \& Tang, 2013).

Niu et al. (2011) concluíram que a principal causa das emissões de $\mathrm{CO}_{2}$ é o consumo de energia, especialmente nos países em desenvolvimento. Ang (2008) também afirma que a emissão de $\mathrm{CO}_{2}$ apresenta uma relação negativa com o crescimento econômico, concluindo assim um feedback negativo do sistema.

A relação entre o investimento em infraestrutura e o consumo de energia é de caráter direto e proporcional, ou seja, ao aumentar os níveis de investimento em infraestrutura de transporte, o consumo energético também é elevado, pois ocorrerá um aumento nas atividades de transporte da região. O consumo de energia apresenta uma relação positiva com a emissão de $\mathrm{CO}_{2}$, a emissão de $\mathrm{CO}_{2}$ possui uma relação negativa com o crescimento econômico, e o crescimento econômico apresenta uma relação proporcional com o investimento em infraestrutura, concluindo assim outro feedback negativo do sistema (Achour \& Belloumii, 2016).

Por fim, o último feedback é composto pela relação direta e proporcional entre o crescimento econômico, investimento em infraestrutura de transporte, valor adicionado ao transporte, consumo de energia, emissão de $\mathrm{CO}_{2}$, e a relação negativa entre emissão de $\mathrm{CO}_{2}$ com o crescimento econômico. $\mathrm{O}$ 
valor adicionado ao transporte é um dado estatístico que representa o quanto o setor de transporte gerou de riqueza para o país. Vale destacar que um maior investimento em infraestrutura de transporte contribui para o aumento das atividades inerentes ao setor, o que coopera positivamente com o valor agregado do setor de transporte, que, consequentemente, demandará uma maior utilização energética (Frischtak \& Mourão, 2017). A Figura 1 descreve o comportamento entre as variáveis utilizadas para desenvolver o modelo proposto.

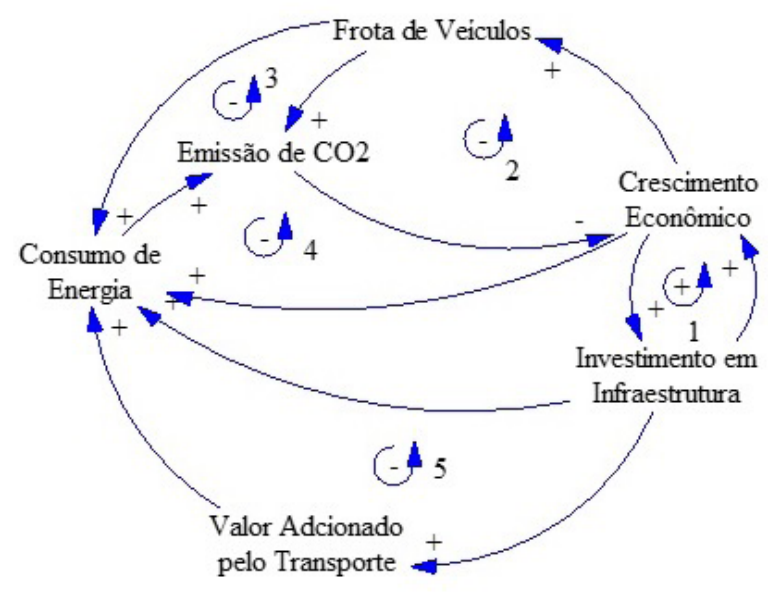

FIGURA 1 - Diagrama de causa e efeito.

FONTE: Elaborado pelos autores.

\section{Diagrama de estoque e fluxo}

Com base na fundamentação teórica apresentada no diagrama de causa e efeito, elaborou-se o diagrama de estoque e fluxo. Algumas relações apresentadas no diagrama de causa e efeito não foram estruturadas no diagrama de estoque fluxo devido à complexidade em modelar matematicamente essas relações, visto que, para quantificá-las, questões econômicas complexas devem ser consideradas, o que foge do escopo definido no presente artigo.

Para melhor compreensão do modelo, o diagrama de estoque e fluxo será apresentado em três submodelos A, B e C. No Submodelo A são calculados os seguintes estoques: PIB, a contribuição do setor de transporte ao PIB (valor adicionado pelo transporte) e os investimentos destinados à infraestrutura do setor de transporte no Brasil (investimento em infraestrutura). Os estoques Investimentos em Infraestrutura e Valor adicionado pelo Transporte dependem do PIB para ser calculados; as demais variáveis podem ser visualizadas na Figura 2.

O PIB é representado como um estoque que acumula ao longo do período sua variação monetária, somado o valor inicial do estoque no período $\left(P I B_{0}\right)$, conforme demonstrado na Equação 1.

$\mathrm{PIB}=\int_{\mathrm{t}_{0}}^{\mathrm{t}}$ (PIB + variação anual do PIB) $\mathrm{dt}+P I B_{0}$ (Equação 1)

$\mathrm{O}$ estoque valor adicionado pelo transporte refere-se à contribuição do setor de transporte ao PIB brasileiro. De acordo com Achour \& Belloumi (2016), o valor adicionado ao transporte representa o quanto de valor o setor de transporte gera para o país. Ele acumula a variação do valor adicionado ao transporte ao longo do tempo por meio do fluxo de variação do valor adicionado pelo transporte (vvat) a

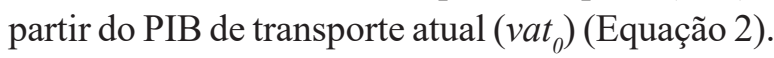

Valor adicional pelo transporte $=\int_{\mathrm{t}_{\mathrm{o}}}^{\mathrm{t}}($ Vvat $) \mathrm{dt}+v a t_{0}$ (Equação 2)

Os investimentos em infraestrutura no Brasil são definidos como porcentagem do PIB, assim, o estoque é acumulado por meio do fluxo de inves- 
timentos anual (investir) a partir do montante de investimento inicial (invinf ${ }_{0}$ ) (Equação 3). Os investimentos empregados na infraestrutura servirão de base para o cálculo da extensão de via rodoviária proposta pelo modelo.

Investimento Infraestrutura $=\int_{\mathrm{t}}($ investir $) \mathrm{dt}+$ invinf $_{0}$ (Equação 3)

No Submodelo B, é proposta uma relação entre os investimentos no setor de transporte no Brasil e sua conversão em extensão de vias, mais precisamente, em rodovias pavimentadas. Para isso, utilizou-se o estoque Investimento em Infraestrutura para determinar a quantidade de rodovias pavimentadas anualmente. Essas rodovias sofrem desgastes ao longo do tempo, o que impacta na extensão de quilômetros pavimentados total. Para simular um desgaste das rodovias federais brasileiras, utilizou-se a frota de veículos circulante no Brasil. A partir dela foi estimado um fluxo médio anual usado para calcular o desgaste. A Figura 3 ilustra os estoques, fluxos e variáveis do Submodelo B.

$\mathrm{O}$ estoque infraestrutura é dado em quilômetros e é calculado por meio da integração da diferença entre as taxas construir (const) e desgastar (desg) para um dado período, a partir da infraestrutura atual (inf), conforme Equação 4.

Infraestrutura $=\int_{t}($ const-desg $) \mathrm{dt}+\mathrm{inf}_{0}$ (Equação 4)

Os estoques Caminhões, Ônibus, Motos, Carros e Comerciais leves representam a frota brasileira de veículos que utilizam combustíveis fósseis, etanol e biodiesel. A Equação 5 representa de forma genérica como esses estoques foram obtidos para cada tipo de veículo.

Tipo de veículo $=\int($ variação tipo de veículo $) \mathrm{dt}+$ quantidade inicial $_{0}$

(Equação 5)

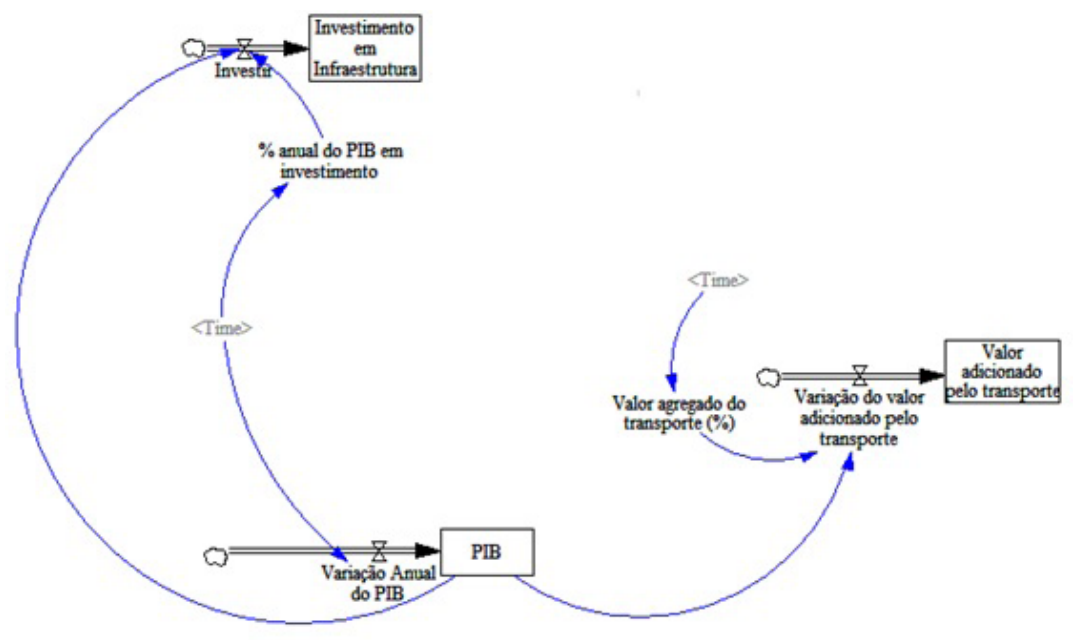

FIGURA 2 - Diagrama de estoque e fluxo - Submodelo A.

FONTE: Elaborado pelos autores. 


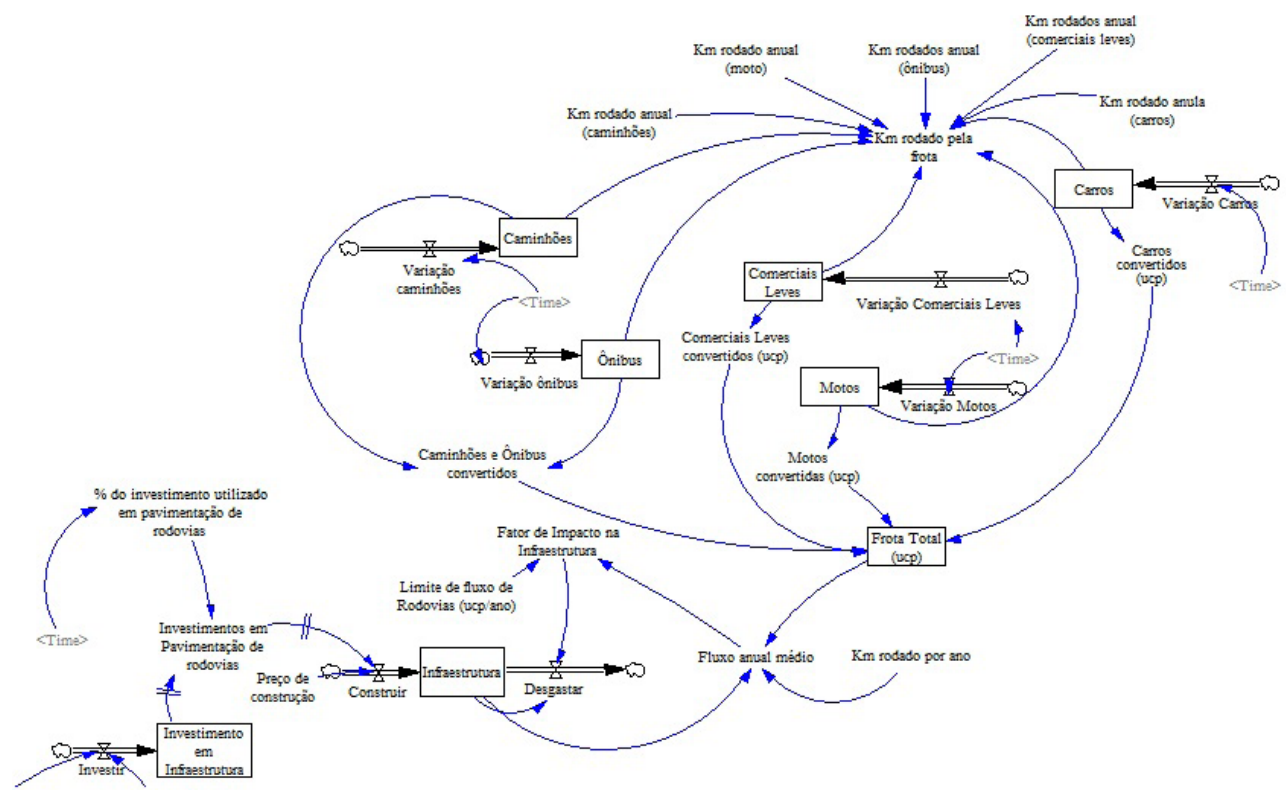

FIGURA 3 - Diagrama de estoque e fluxo - Submodelo B.

FONTE: Elaborado pelos autores.

Ainda no presente submodelo, é calculada a variável auxiliar quilômetro rodado pela frota (kmrodfrota), a qual servirá de parâmetro para o submodelo $\mathrm{C}$ expressa de forma genérica na Equação 6, onde n refere-se a cada tipo de veículo incluído no modelo.

Kmrodfrota $=\sum$ Veículon $*$ Km rodado anual (n) (Equação 6)

O Submodelo C compreende as variáveis e equações que determinam o valor total das emissões de $\mathrm{CO}_{2}$ decorrentes das atividades do modal rodoviário no Brasil, conforme ilustrado da Figura 4. $\mathrm{O}$ estoque $\mathrm{CO}_{2}$ emitido pelo modal acumula as emissões oriundas da queima dos combustíveis dos veículos. É dado pela integração da soma das taxas de emissão de $\mathrm{CO}_{2}$ dos combustíveis utilizados no modal rodoviário conforme Equação 7.

$\mathrm{CO} 2=\int_{\mathrm{t}_{\mathrm{t}}}^{\mathrm{t}}\left(\sum\right.$ Taxa de Emissão de CO2 combustível $\left._{\mathrm{n}}\right) \mathrm{dt}$ $+\mathrm{CO}_{\mathrm{emitido}}$

(Equação 7)

A Figura 4 detalha as variáveis, fluxos e estoques que compõem esse submodelo.

Todos os três submodelos se relacionam por meio dos indicadores que avaliam o impacto do PIB nas emissões de $\mathrm{CO}_{2}$ que, por sua vez, determinam a intensidade de emissão de $\mathrm{CO}_{2}$ pelo modal rodoviário. Além disso, a intensidade energética avalia a relação entre o consumo energético necessário para um determinado incremento no PIB pelo setor de transportes, conforme Figura 5. 


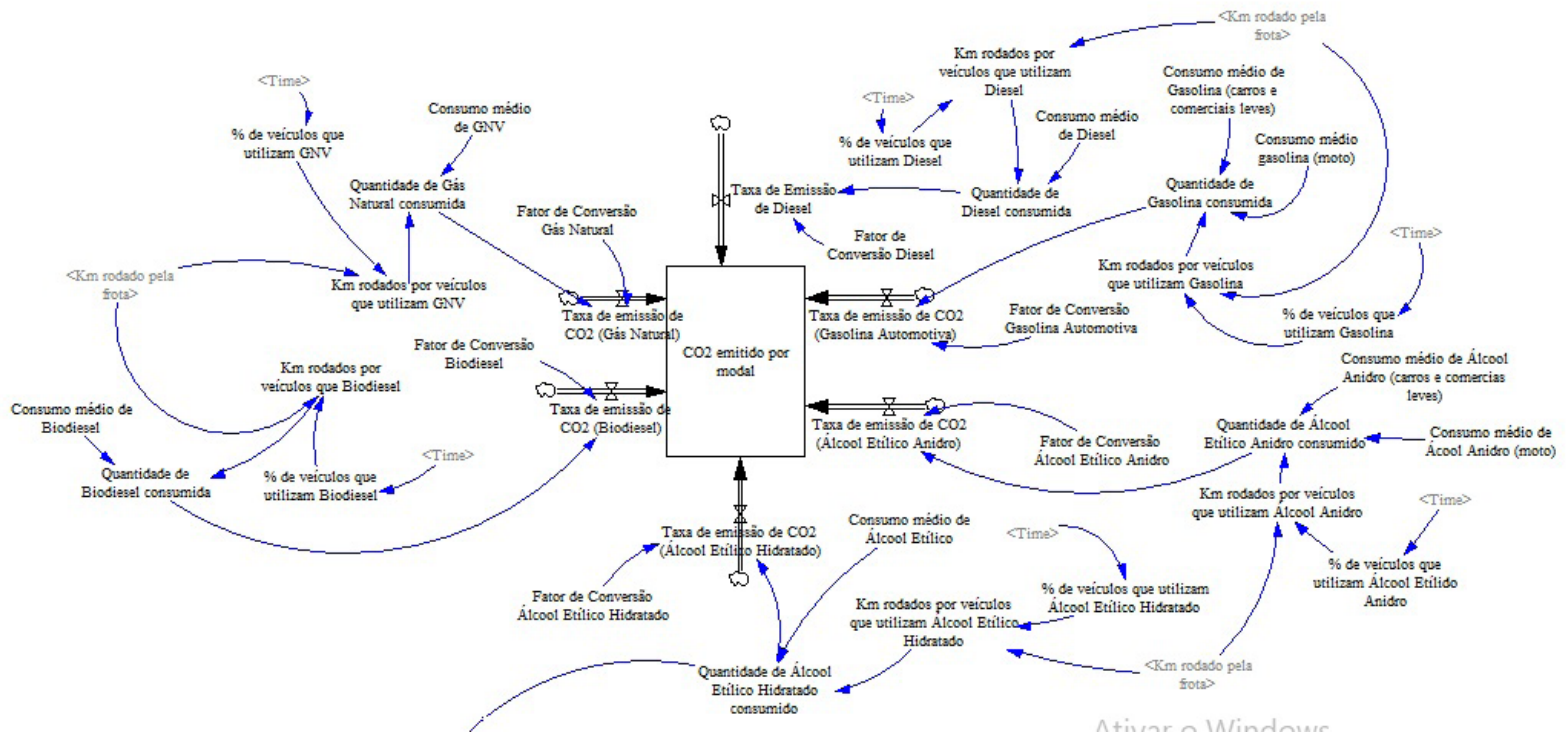

FIGURA 4 - Diagrama estoque e fluxo - Submodelo C.

FONTE: Elaborado pelos autores.

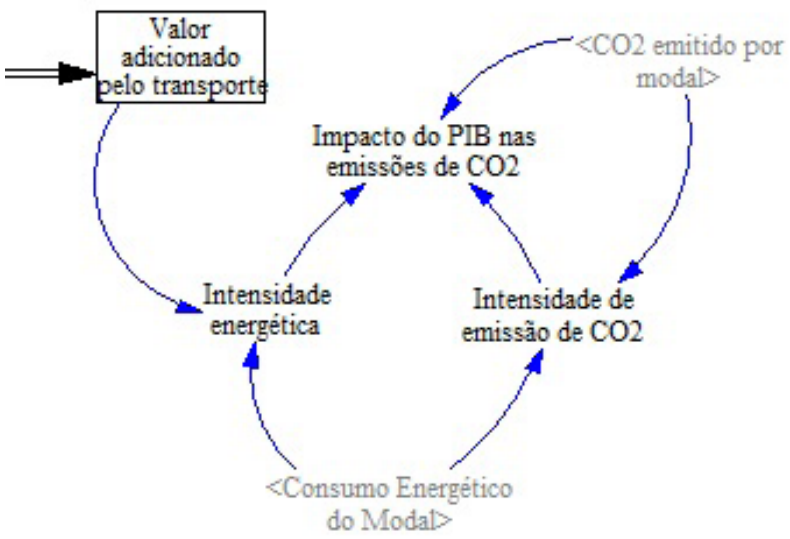

FIGURA 5 - Indicadores de análise do modelo proposto.

FONTE: Elaborado pelos autores. 


\section{Cenários propostos}

A partir do modelo testado, devidamente parametrizado e com apoio de dados passados, podem-se estabelecer cenários analíticos para os submodelos propostos. Os cenários propostos buscam avaliar os impactos na emissão de $\mathrm{CO}_{2}$ e utilização energética dos seguintes subgrupos: PIB, investimentos em infraestrutura rodoviária, investimentos em pavimentação de rodovias e frota de veículos.

O subgrupo de cenário do PIB refere-se aos cenários nos quais os valores anuais do PIB foram variados. O primeiro cenário, o qual foi chamado de cenário base, servirá de referência para comparação dos demais cenários, por se tratar de previsão do governo para os próximos 10 anos. Esse cenário considerou um crescimento anual médio do PIB de 2\% para os próximos 10 anos. Os demais parâmetros do modelo foram preenchidos com a média dos valores históricos das variáveis dos anos de 2000 a 2016. No Cenário 1, o valor do PIB não sofreu alteração ao longo dos anos, ou seja, representa uma estagnação da economia. As demais variáveis permaneceram inalteradas. No Cenário 2, buscou-se projetar uma perspectiva otimista, em que o PIB brasileiro tem um crescimento de $3,2 \%$ ao ano nos próximos 10 anos. Por último, foi proposto o cenário pessimista (Cenário 3), no qual a variação do PIB anual é de $1 \%$ de crescimento ao ano. As demais variáveis continuaram com os valores inalterados.

No subgrupo Investimentos em Infraestrutura Rodoviária referente aos investimentos destinados ao modal rodoviário de maneira geral, como manutenção, construção e pavimentação de vias, foram estabelecidos mais dois cenários. O Cenário 4 considerou o menor valor investido em porcen- tagem do PIB dos anos de 2000 a 2016 e projetou este percentual para os próximos 10 anos. As demais variáveis continuaram com os valores estabelecidos de acordo com o cenário base. No Cenário 5 , por outro lado, projetou-se o maior percentual de investimento da série história. O subgrupo extensão de rodovias pavimentadas, que envolve somente a parcela de investimentos destinados para a pavimentação de rodovias, seguiu o mesmo raciocínio do subgrupo anterior: no Cenário 6 , foi projetado o menor percentual de investimento realizado na série histórica analisada, enquanto o Cenário 7 propõe o maior patamar de investimento.

No subgrupo Frota de Veículos, foram propostos mais dois cenários, em que a variação do número de veículos foi modificada. No Cenário 8 , foram considerados os menores patamares de crescimento no período de 2000 a 2016 para cada tipo de veículo constante no modelo. Esse valor foi replicado para o período de simulação estipulado e as demais variáveis, assim como nos outros subgrupos, permaneceram de acordo com o cenário base estabelecido. No Cenário 9, lógica semelhante foi

TABELA 1 - Resumo dos cenários propostos.

\begin{tabular}{lccc}
\hline \multicolumn{1}{c}{ Cenário } & Pessimista & Estagnado & Otimista \\
\hline Base & - & - & - \\
1 (PIB) & & $\mathrm{X}$ & \\
2 (PIB) & & & $\mathrm{X}$ \\
3 (PIB) & $\mathrm{X}$ & & \\
4 (Inv. Inf.) & $\mathrm{X}$ & & $\mathrm{X}$ \\
5 (Inv. Inf.) & & \\
6 (Pav.) & $\mathrm{X}$ & $\mathrm{X}$ \\
7 (Pav.) & & \\
8 (frota) & $\mathrm{X}$ & & $\mathrm{X}$ \\
9 (frota) & & & \\
\hline
\end{tabular}

FONTE: Elaborado pelos autores. 
aplicada, porém, ao invés de considerar os menores patamares de crescimento, utilizou-se as maiores projeções de crescimento de cada categoria de veículos.

\section{Resultados}

No primeiro subgrupo, os valores do PIB foram variados (Cenários 1, 2 e pessimista) e comparados com o Cenário base. Em relação à infraestrutura, a variação nos valores do PIB tem pouca interferência na quantidade de quilômetros pavimentados, sendo, até 2022, quase inexistente quando comparados ao Cenário Base. Esse fato deve-se aos percentuais de investimentos em infraestrutura rodoviária e de pavimentação que permaneceram constantes nos cenários simulados, o que indica que um aumento no PIB não implicará diretamente no aumento de rodovias pavimentadas, visto que tanto no Cenário 1,2 e 3 houve aumento semelhante da quantidade de quilômetros pavimentados conforme ilustrado na Figura 6.

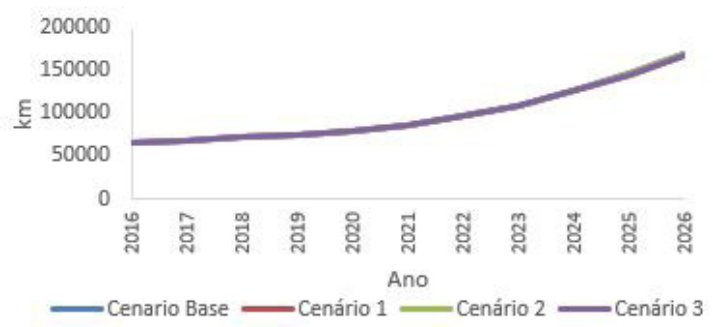

FIGURA 6 - Comportamento extensão de vias pavimentadas nos cenários base, 1,2 e 3 .

FONTE: Elaborado pelos autores.
Não foi observada nenhuma alteração nos valores de emissão de $\mathrm{CO}_{2}$ para os cenários com variações no PIB, conforme Figura 7. Esse comportamento é esperado, pois no modelo não foi possível quantificar a relação entre PIB e frota de veículos. Esses dois fatores não apresentaram relação de causalidade quando estudados no escopo do problema proposto, o que impossibilitou o equacionamento dessa relação, uma vez que, para que fosse possível, seria necessário considerar diversos fatores de cunho econômico, o que afastaria o problema do viés definido.

Contudo, apesar da variação do PIB proposta nos diferentes cenários simulados, nota-se um crescimento na quantidade de $\mathrm{CO}_{2}$ emitida pelo modal, representando em termos numéricos um acréscimo de 7,5\% no nível de emissão em 10 anos. De acordo com EPE (2017), a previsão no aumento do consumo energético é de $5 \%$ até 2026 , portanto, caso a frota de veículos continue aumentando nos patamares atuais e caso medidas mitigadoras de 
consumo energético não sejam tomadas, é possível que esse consumo energético seja ainda maior.

Esse resultado vai de encontro com a meta estabelecida pelo Governo Federal na cúpula da ONU (União das Nações Unidas) sobre desenvolvimento sustentável em 2015, em que o país se comprometeu a reduzir em $43 \%$ a emissão de gases do efeito estufa até 2030. Vale destacar que o setor de transporte no ano de 2016 representou $45,3 \%$ das emissões totais de $\mathrm{CO}_{2}$ no Brasil, sendo o modal rodoviário responsável por $92 \%$ das emissões do setor (EPE, 2017), o que demonstra a importância do mesmo nos indicadores de emissão nacional. Portanto, ações que minimizem o impacto desse modo nas emissões devem ser planejadas para não comprometer o alcance dessa meta.

No segundo subgrupo, foram variados os parâmetros de investimentos em infraestrutura rodoviária (Figura 8). No Cenário 4 percebe-se uma retração na quantidade de quilômetros pavimentados em relação ao Cenário Base. Em 2026 tem-se 152.523 quilômetros pavimentados no Cenário 4, contra 169.757 quilômetros de rodovias pavimentas do Cenário Base, ou seja, uma diferença de $10 \%$ a menos na malha rodoviária pavimentada no Cenário 4. Assim, pode-se dizer que, se investindo $1 \%$ do PIB ao ano em pavimentação de estradas, o crescimento na extensão de rodovias pavimentadas é desacelerado. De acordo com Chandran \& Tang (2013), isso traz diversos prejuízos para a economia do país, dada a dependência existente pelo modal para transporte de cargas e passageiros. Essa desaceleração na evolução de rodovias pavimentadas acarretaria em perdas econômicas para o país, pois ocasionaria um aumento nos custos do frete, por exemplo.

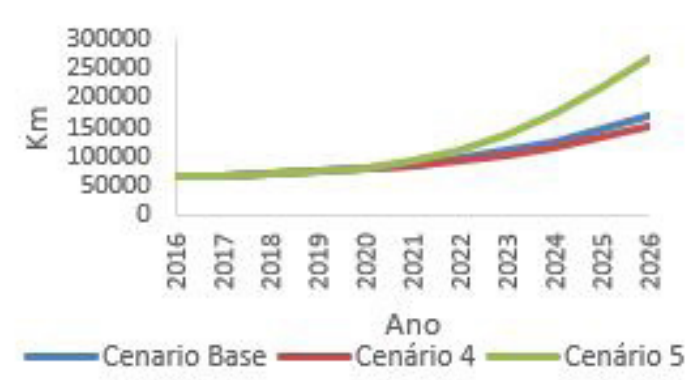

FIGURA 8 - Comportamento extensão de vias pavimentadas nos Cenários base, 4 e 5 .

FONTE: Elaborado pelos autores.

Em termos numéricos, investindo-se 3\% ao ano do PIB em infraestrutura rodoviária no Cenário 5 (otimista), é possível quase quadruplicar a quantidade de quilômetros pavimentados em 10 anos, considerando que a extensão rodoviária do país permaneça a mesma de 2016. Esse fator torna o setor mais eficiente e menos poluidor, visto que, de acordo com Bartholomeu \& Caixeta Filho (2008), a qualidade da rodovia gera um aumento em cerca de $6 \%$ no consumo de combustível e, consequentemente, aumenta os níveis de emissão de $\mathrm{CO}_{2}$.

Dessa forma, assim como apresentado no subgrupo anterior, os níveis de emissão de $\mathrm{CO}_{2}$ não apresentaram diferenças em termos de comportamento. Porém, percebe-se em todos os cenários uma tendência de crescimento, o que demonstra que a precariedade na infraestrutura também interfere nos níveis de emissão de $\mathrm{CO}_{2}$, mesmo que com menor intensidade e mais indiretamente (Figura 9).

No terceiro subgrupo, os percentuais de investimentos em extensão de vias pavimentados foram alterados, conforme representado no Figura 10. Pode-se notar comportamento similar ao observado 
no segundo subgrupo, ou seja, tem relação direta com a quantidade de quilômetros pavimentados e mantém os níveis crescentes de emissão de $\mathrm{CO}_{2}$. No Cenário 6 (pessimista) é observado um crescimento inexpressivo da extensão de quilômetros pavimentados. Em 10 anos, aumenta-se apenas 1\% a extensão de rodovias pavimentadas. Isso significa que os patamares de investimentos nesse período seriam suficientes apenas para manter a extensão de vias existentes, porém insuficientes para promover um desenvolvimento do modal. No Cenário 7 (otimista), há aumento de $84 \%$ de extensão de rodovias pavimentadas no período simulado, caso sejam destinados $28,1 \%$ dos investimentos no modal rodoviário para pavimentação de rodovias. Isso ocasionaria um aumento de $10 \%$ na quantidade de quilômetros pavimentados considerando que a extensão rodoviária do país permaneça a mesma de 2016. Dessa forma, assim como esperado, há uma relação direta entre investimentos em infraestrutura e extensão da malha rodoviária. Porém, pode-se dizer que essa relação é menos relevante se comparada à apresentada no subgrupo anterior.

No quarto subgrupo, em que a frota de veículos foi variada, notou-se diferença entre os Cenários

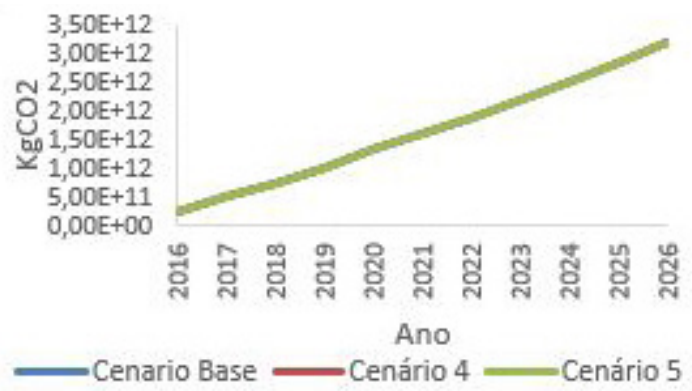

FIGURA 9 - Comportamento emissão de $\mathrm{CO}_{2}$ nos Cenários base, 4 e 5 . FONTE: Elaborado pelos autores.

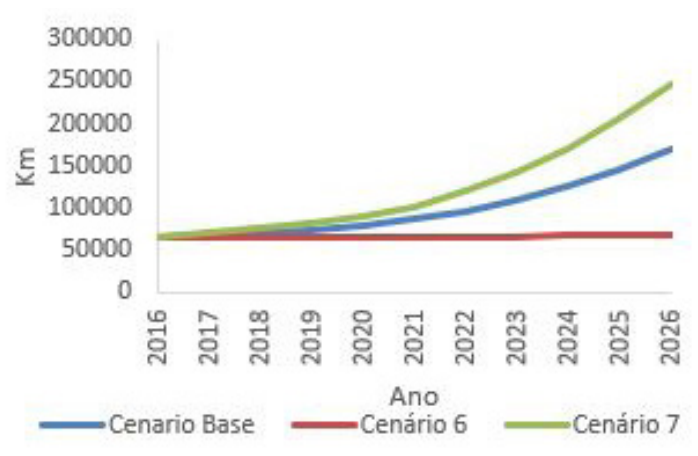

FIGURA 10 - Variações nos Investimentos em Pavimentações de Rodovias Cenários base, 6 e 7.

FONTE: Elaborado pelos autores.

8 e 9 simulados na emissão de $\mathrm{CO}_{2}$. Em relação à infraestrutura, não houve diferença nos cenários que compõem esse subgrupo (Figura 11). Como os percentuais de investimentos em infraestrutura e pavimentação de rodovias foram mantidos conforme o Cenário base, verifica-se que os investimentos médios praticados no Cenário base são suficientes para manter um crescimento na extensão de quilômetros pavimentados no período simulado mesmo com o crescimento da frota nos níveis projetados.

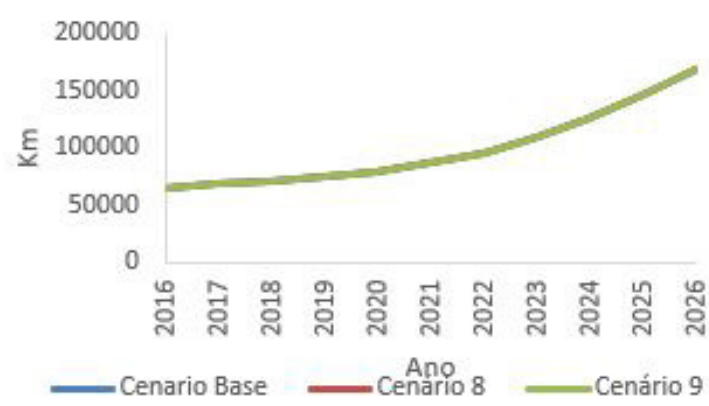

FIGURA 11 - Comportamento extensão de vias pavimentadas Cenários Base, 8 e 9.

FONTE: Elaborado pelos autores 
Com relação à emissão de $\mathrm{CO}_{2}$, foi observado um aumento na quantidade de $\mathrm{CO}_{2}$ emitida no Cenário 9 frente aos outros cenários. Esse aumento tende a crescer mais rapidamente a partir do ano de 2022 (Figura 12). Essa diferença corrobora com a literatura de que a frota de veículos possui uma forte relação com os níveis de emissão de $\mathrm{CO}_{2}$. Em termos numéricos, e já corrigindo a amplificação que o modelo faz no período de 10 anos, ou seja, $3 \%$ de amplificação, no Cenário 8 (pessimista), há um aumento de 12 vezes na quantidade de emissão comparada com os níveis de 2016. No Cenário 9 (otimista), esse aumento é ainda maior, de 14,5 vezes em relação aos níveis de 2016. Esse cenário reforça a necessidade de investimento em alternativas para o setor de transporte para que o Brasil consiga atingir suas metas de emissão, entre elas, investir em modais menos poluentes para que a dependência do modal rodoviário seja reduzida. Vale destacar que algumas medidas para priorizar os modais não motorizados e coletivos de transporte em detrimento do transporte individual motorizado já foram realizadas, como a Política Nacional de Mobilidade Urbana da Lei 12.587 de 3 de janeiro de 2012 .

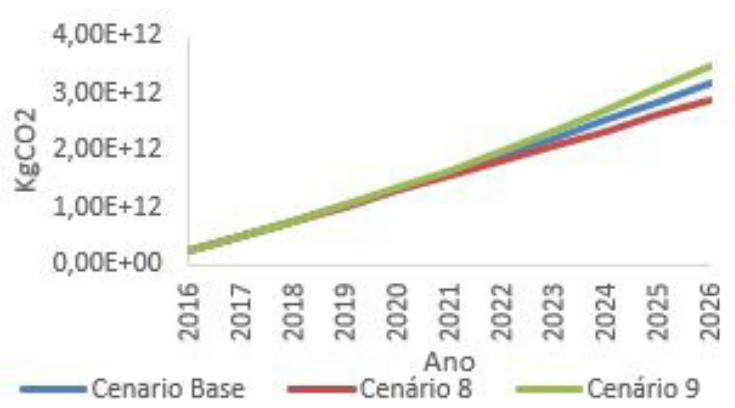

FIGURA 12 - Comportamento emissão de CO2 nos Cenários 8 e 9. FONTE: Elaborado pelos autores.

\subsection{Comparação entre cenários}

A Tabela 2 demonstra os valores de saída da simulação para o ano de 2026 nos diferentes cenários propostos. Com relação à infraestrutura, alterações ocorreram nos Cenários 1, 2, 3, 4, 5 e 6 e 7, pois alterações no PIB influenciam investimentos em infraestrutura rodoviária e investimentos em extensão de vias pavimentadas, variáveis que afetam diretamente a quantidade de quilômetros pavimentados disponível do modal rodoviário.

No Cenário 4 ocorreu o maior valor do estoque de infraestrutura. Pode-se dizer então, que o maior nível de investimento em infraestrutura rodoviária tem maior impacto na quantidade de quilômetros pavimentados, mesmo se comparado com o cenário otimista dos investimentos destinados somente à pavimentação (Cenário 6). Assim, conclui-se que é preferível aumentar os investimentos em infraestrutura rodoviária de maneira global, desde que se mantenha a média de pavimentação de rodovias, ao invés de aumentar somente o investimento destinado à pavimentação. Porém, sabe-se que manter esses patamares de investimentos não é simples, ainda mais considerando a recente recessão econômica vivenciada no país.

Com relação à emissão de $\mathrm{CO}_{2}$, o maior nível de emissão observado foi no Cenário 8. Isso significa que, dentre os fatores que afetam diretamente os níveis de emissão de dióxido de carbono, o aumento da frota é o que tem maior impacto. Dessa forma, políticas que visam a redução na taxa de aumento da frota circulante, como maiores investimentos para aumentar a atratividade do transporte coletivo, seriam desejáveis, principalmente se forem acompanhadas de políticas que promovam uma maior diversificação da matriz de transportes no Brasil. 


\begin{tabular}{lcccc}
\hline Cenários & $\begin{array}{c}\text { Vias Pavimentadas } \\
(\mathbf{K m})\end{array}$ & $(\mathbf{\Delta})$ & $\mathbf{C O}_{2}\left(\mathbf{k g C O}_{2}\right) \mathbf{1 0}^{6}$ & $(\boldsymbol{\Delta})$ \\
\hline Base & $\mathbf{1 6 9 . 7 5 7}$ & & 3.202 .930 & $0 \%$ \\
$\mathbf{1}$ & $\mathbf{1 6 8 . 1 2 7}$ & $\mathbf{- 1 \%}$ & 3.202 .930 & $0 \%$ \\
$\mathbf{2}$ & $\mathbf{1 7 0 . 7 7 1}$ & $\mathbf{1 \%}$ & 3.202 .930 & $0 \%$ \\
$\mathbf{3}$ & $\mathbf{1 6 8 . 2 0 7}$ & $\mathbf{- 1 \%}$ & 3.202 .930 & $0 \%$ \\
$\mathbf{4}$ & $\mathbf{1 5 2 . 5 2 3}$ & $\mathbf{- 1 0 \%}$ & 3.202 .930 & $0 \%$ \\
$\mathbf{5}$ & $\mathbf{2 6 7 . 4 2 1}$ & $\mathbf{5 8 \%}$ & 3.202 .930 & $0 \%$ \\
$\mathbf{6}$ & $\mathbf{6 8 . 8 2 9}$ & $\mathbf{- 5 9 \%}$ & 3.202 .930 & $0 \%$ \\
$\mathbf{7}$ & $\mathbf{2 4 5 . 8 6 2}$ & $\mathbf{4 5 \%}$ & 3.202 .930 & $-9 \%$ \\
$\mathbf{8}$ & 169.757 & $\mathbf{0 \%}$ & $\mathbf{2 . 8 9 8 . 7 1 0}$ & $9 \%$ \\
$\mathbf{9}$ & 169.757 & $\mathbf{0 \%}$ & $\mathbf{3 . 4 9 7 . 8 1 0}$ & \\
\hline
\end{tabular}

FONTE: Elaborado pelos autores.

Medidas de incentivo a mudanças nos modais de transporte desempenham um papel expressivo na redução do consumo de energia, e das emissões de gases do efeito estufa associadas ao setor. Elas incluem, além da ampliação das redes de transporte público e incentivos fiscais à utilização do transporte público, a utilização de modais de transporte não motorizados, pedágios diferenciados, incentivo às caminhadas e ao ciclismo e planejamento da mobilidade urbana (ANP, 2014).

A política governamental de comercialização de combustíveis pode contribuir para redução da quantidade de veículos circulantes no Brasil. Quanto mais caro o diesel em relação ao preço da gasolina maior utilização de transporte individual motorizado e menor uso do transporte público. Estes preços exercem pouca influência na decisão de compra de um veículo privado, mas geram influência no nível de utilização destes veículos no dia a dia e, consequentemente, o nível total de emissão de poluentes. Almeida et al. (2015) explicam que, desde o monopólio da Petrobras na comercialização de derivados de petróleo no Brasil, o governo vem imprimindo aumentos reais para o diesel, muito superiores aos aumentos da gasolina. Nos últimos 10 anos, o preço do diesel subiu 72\% acima da inflação, enquanto a gasolina subiu apenas 14\%. Dessa forma, o transporte público torna-se menos atrativo e acessível em relação ao transporte individual.

Políticas de incentivo à motorização no país também contribuem para o aumento das emissões. O Brasil apresenta uma taxa de motorização (quantidade de veículos para cada 100 habitantes) muito inferior à dos países desenvolvidos e também aos em desenvolvimento. Nos Estados Unidos, a taxa de motorização é de 83 veículos para cada 100 habitantes, na Argentina, 21 e no Brasil, 14 (ANFAVEA, 2012). Isso indica que há um grande potencial de crescimento nessa taxa de motorização do Brasil. A política de redução de IPI para veículos aplicada em 2008 e 2012 triplicou o aumento da capacidade instalada da indústria automobilística 
no Brasil (Lukic, 2015). Esse fenômeno ocorre com mais força nos países em desenvolvimento, já que ainda possuem baixa taxa de motorização em relação aos países desenvolvidos. Nos períodos de recuperação econômica, a indústria automobilística é uma das primeiras a sentir os efeitos positivos, transformando a demanda reprimida em demanda manifesta (Carvalho, 2011; Wilbert et al., 2014), por isso, ações governamentais nesse sentido, devem ser avaliadas com cautela do ponto de vista de emissão de $\mathrm{CO}_{2}$.

Outra medida sancionada pela medida provisória $n^{0} 847$, de 06 de julho de 2018, que pode contribuir para mitigar as emissões de $\mathrm{CO}_{2}$, é programa do Governo Federal denominado Rota 30. O programa prevê redução do Imposto sobre Produtos Industrializados (IPI) para veículos que superarem metas de segurança e eficiência energética. Inicialmente, haverá queda de $25 \%$ a até $7 \%$ para carros híbridos e elétricos. Para os demais carros, poderá haver redução na alíquota de 1 a 2 pontos percentuais a partir de 2023, se eles superarem as metas estabelecidas no programa. Essa medida tem como objetivo estimular novas tecnologias na produção de veículos no Brasil (Brasil, 2018).

Outro fator que pode auxiliar no processo de redução de recursos energéticos pelo modal rodoviário é o investimento em infraestrutura rodoviária. Estudo realizado pelo Departamento Nacional de Infraestrutura de Transporte (DNIT) mostra que uma rodovia em estado ruim de conservação acarreta em um aumento de 58\% no consumo de combustíveis (CNT, 2001). Nesse contexto, a concessão de rodovias é uma saída para a realização de investimentos no modal rodoviário, principalmente no atual cenário brasileiro de recessão da economia, o qual reduz a capacidade do governo de financiar obras de grande porte.

Tornar o uso de energia mais eficiente no setor de transporte é um problema que vem sendo discutido na União Europeia. Isso levou à adoção de diversas medidas: substituição de modais de transportes, redução do consumo específico de veículos leves e pesados, encorajamento da aquisição de veículos mais limpos, incentivo a mudanças nos hábitos dos motoristas, entre outros. A redução da demanda pelos serviços de transportes também já é considerada pelos formuladores de políticas europeus um ponto-chave para a redução do consumo (ANP, 2014).

O Brasil precisa investir em políticas com o objetivo de encorajar a aquisição de veículos mais eficientes do ponto de vista do consumo de energia, a exemplo do que foi proposto no programa Rota 30. Esses incentivos podem ser feitos por meio de promoção de impostos diferenciados em função da eficiência no consumo e das emissões de $\mathrm{CO}_{2}$, por exemplo, o que pode também ajudar no processo de renovação de frota de carros muito antigos, que possuem consumo de energia elevado.

O encorajamento dos motoristas no sentido de dirigir mais eficiente também pode acarretar em economia de combustíveis. De modo semelhante, o transporte solidário, quando amplamente incentivado com o objetivo de promover mudanças nos hábitos de motoristas e passageiros, pode trazer benefícios para aplacar o consumo energético do setor (IPEA, 2016).

O Brasil, a exemplo de países europeus, vem tentando criar e implantar medidas para buscar um desenvolvimento sustentável no setor de transporte, principalmente no modal rodoviário, devido à dependência que o país possui do mesmo. Porém, 
essas médias ainda caminham a passos lentos, principalmente por divergências nos interesses políticos e econômicos que são atualmente os principais entraves para o desenvolvimento do país. Assim sendo, o Estado precisa assumir efetivamente seu papel regulador nos aspectos relacionados à utilização de energia pelo modal rodoviário. Intensificar a fiscalização e sanções a empresas, estados e municípios que não atenderem ou se adequarem a legislação e programas vigentes, assim como efetivar os incentivos para aqueles que cumprirem seu papel mediante as iniciativas de otimização do uso energético do setor, pode ser um início para o atingimento das metas de eficiência energética e emissão de $\mathrm{CO}_{2}$ almejadas.

\section{Considerações finais}

Mundialmente, há um esforço conjunto para que as nações consigam alcançar um desenvolvimento sustentável, com ganhos econômicos a partir de menores índices de utilização energética de fontes emissoras de $\mathrm{CO}_{2}$. Destarte, um método qualitativo, combinado à abordagem de dinâmica de sistemas, apresenta-se como uma útil ferramenta para formulações e planejamentos voltados à busca de um desenvolvimento sustentável.

Por meio da discussão teórica realizada, foi possível entender como as variáveis crescimento econômico, investimento em infraestrutura, emissão de $\mathrm{CO}_{2}$ e frota de veículos para o modal rodoviário se relacionam no Brasil de maneira sistêmica e temporal. Após buscas na literatura disponível, pode-se perceber a existência de uma lacuna sobre estudos que abordem essas relações, principalmente no caso do Brasil.
Os resultados das simulações mostraram que algumas ações interferem em maior ou menor grau no índice de emissão de $\mathrm{CO}_{2}$. Essas ações devem ser consideradas ao tomar decisões no que tange a redução de emissões e à busca por crescimento econômico. Pode-se perceber que, devido à dependência existente pelo modal rodoviário, o desafio fica ainda maior para o Brasil. Contudo, é possível alcançar maiores patamares de crescimento econômico junto com um crescimento moderado nas emissões de $\mathrm{CO}_{2}$. Para isso, faz-se necessário o planejamento da utilização de combustíveis, uma maior diversificação da utilização dos diferentes modais disponíveis no país e um melhor investimento em infraestrutura rodoviária. Além disso, a dinâmica de expansão de veículos elétricos, bem como o incentivo governamental para redução de impostos, são elementos que não foram diretamente incorporados no modelo apresentado, e seguem como sugestão para estudos futuros.

O modelo de dinâmica de sistemas criado pode ser implementado em outros países a partir da inserção de dados de entrada referentes a cada realidade, e os resultados podem ser comparados com o trabalho atual. Entretanto, o modelo proposto pode ser aperfeiçoado. Em termos econômicos, sugere-se buscar inserção de variáveis que relacionem o PIB com a frota de veículos, para que seja possível uma avaliação direta dessas duas variáveis. Além disso, os custos de manutenção de rodovias e seu impacto na extensão rodoviária do Brasil não foram considerados neste estudo. Da mesma forma, o impacto do transporte de cargas na degradação do pavimento pode ser considerado, visto a dimensão que o mesmo possui no Brasil. 


\section{Agradecimentos}

Os autores agradecem o suporte financeiro do Conselho Nacional de Desenvolvimento Científico e Tecnológico- CNPq (Processo 308411/2018-8) e da Universidade Federal do Espírito Santo.

\section{Referências}

Abbas, K. A.; Bell, M. G. System dynamics applicability to transportation modeling. Transportation Research Part A: Policy and Practice, 28(5), 373-390, 1994. doi: 10.1016/0965-8564(94)90022-

Achour, H.; Belloumi, M. Investigating the causal relationship between transport infrastructure, transport energy consumption and economic growth in Tunisia. Renewable and Sustainable Energy Reviews, 56, 988-998, 2016. doi: 10.1016/j.rser.2015.12.023

Almeida, E. L. F.; Oliveira, P. V.; Losekann, L. Impactos da contenção dos preços de combustíveis no Brasil e opções de mecanismos de precificação. Revista de Economia Política, 35(3), 531-556, 2015. doi: 10.1590/0101-31572015v35n0 $3 \mathrm{a} 09$

Amann, E.; Baer, W.; Trebat, T.; Lora, J. V. Infrastructure and its role in Brazil's development process. The Quarterly Review of Economics and Finance, 62, 66-73, 2016. doi: 10.1016/j.qref.2016.07.007

ANFAVEA - Associação Nacional dos Fabricantes de Veículos Automotores. Anuário da Indústria Automobilística Brasileira (Brazilian Automotive Industry Yearbook), 2012. Diponível em: < http://www.virapagina.com.br/ anfavea2012/>. Acesso em: ago. 2018.

Ang, J. B. $\mathrm{CO}_{2}$ emissions, energy consumption, and output in France. Energy Policy, 35(10), 4772-4778, 2007. doi: 10.1016/j.enpol.2007.03.032

Ang, J. B. Economic development, pollutant emissions and energy consumption in Malaysia. Journal of Policy Modeling, 30(2), 271-278, 2008. doi: 10.1016/j.jpol- $\bmod .2007 .04 .010$

ANP - Agência Nacional de Petróleo. Eficiência Energética do Setor de Transporte da União Europeia, 2014. Disponível em: < https://www.anp.gov.br/SITE/acao/downloa$\mathrm{d} /$ ?id=69992 $>$. Acesso em: ago. 2018.

Azlina, A. A.; Law, S. H.; Mustapha, N. H. N. Dynamic linkages among transport energy consumption, income and CO2 emission in Malaysia. Energy Policy, 73, 598-606, 2014. doi: 10.1016/j.enpol.2014.05.046

Banister, D. Berechman, Y. Transport investment and the promotion of economic growth. Journal of Transport Geography, 9(3), 209-218, 2001. doi: 10.1590/S010320032008000300006

Bartholomeu, D. B.; Caixeta Filho, J. V. Impactos econômicos e ambientais decorrentes do estado de conservação das rodovias brasileiras: um estudo de caso. Revista de Economia e Sociologia Rural, 46(3), 703-738, 2008. doi: 10.1590/S0103-20032008000300006

Brasil. Medida Provisória $n^{\circ}$ 843, de 06 de julho de 2018. Estabelece requisitos obrigatórios para a comercialização de veículos no Brasil e institui o Programa Rota 2030 Mobilidade e Logística e dispõe sobre o regime tributário de autopeças não produzidas. Brasília: DOU 14/072018.

Carvalho, C. H. R. Emissões Relativas de Poluentes do Transporte Motorizado de Passageiros nos Grandes Centros Urbanos Brasileiros, 2011. Disponível em: < http://www. en.ipea.gov.br/agencia/images/stories/PDFs/TDs/td_1606. pdf $>$. Acesso em: ago. 2018.

Chandran, V. G. R.; Tang, C. F. The impacts of transport energy consumption, foreign direct investment and income on $\mathrm{CO}_{2}$ emissions in ASEAN-5 economies. Renewable and Sustainable Energy Reviews, 24, 445-453, 2013. doi: 10.1016/j.rser.2013.03.054

Chontanawat, J.; Hunt, L. C.; Pierse, R. Does energy consumption cause economic growth? Evidence from a systematic study of over 100 countries. Journal of Policy Modeling, 39, 209-220, 2008. doi: 10.1016/j.jpolmod.2006.10.003

CNT - Confederação Nacional Dos Transportes. Revista CNT, 2001. Disponível em: <http://www.cnt.org.br>. 
Acesso em: ago. 2018.

Coondoo, D.; Dinda, S. Causality between income and emission: a country group-specific econometric analysis. Ecological Economics, 40(3), 351-367, 2002.

Diaz, R.; Behr, J. G.; Ng, M. Quantifying the economic and demographic impact of transportation infrastructure investments: A simulation study. Simulation, 92(4), 377393, 2016. doi: 10.1177/0037549716632343

EPE - EMPRESA PESQUISA ENERGÉTICA. Caracterização do Cenário Macroeconômico: para os próximos 10 anos (2016-2025), 2017. Disponível em: < http://www. epe.gov.br/sites-pt/publicacoes-dados-abertos/publicacoes/ PublicacoesArquivos/publicacao-245/topico-263/DEA\%20 08-16\%20-\%20Cen\%C3\%A1rio\%20macroecon $\% \mathrm{C} 3 \% \mathrm{~B}-$ 4mico\%202016-2025[1].pdf>. Acesso em: jul. 2018.

Fodha, M.; Zaghdoud, O. Economic growth and pollutant emissions in Tunisia: an empirical analysis of the environmental Kuznets curve. Energy Policy, 38(2), 1150-1156, 2010. doi: 10.1016/j.enpol.2009.11.002

Forrester, J. W. "The" model versus a modeling "process". System Dynamics Review, 1, 133-134, 1985.

Frischtak, C. R.; Mourão, J.; O Estoque de Capital de Infraestrutura no Brasil: uma abordagem setorial, 2017. Disponível em: < http://epge.fgv.br/conferencias/modernizacao-da-infraestrutura-brasileira-2017/files/estoque-de-capital-setorial-em-infra-brasil-22-08-2017.pdf $>$. Acesso em: jun. 2018.

Georgiadis, P.; Vlachos, D. The effect of environmental parameters on product recovery. European Journal of Operational Research, 157(2), 449-464, 2004. doi: 10.1016/ S0377-2217(03)00203-0

Ghali, K. H.; El-Sakka, M. I. T. Energy use and output growth in Canada: a multivariate cointegration analisys. Energy Economics, 26(2), 225-238, 2004. doi: 10.1016/ S0140-9883(03)00056-2

Ghosh, S. Examining carbon emissions economic growth nexus for India: a multivariate cointegration approach. Energy Policy, 38(6), 3008-3014, 2010. doi: 10.1016/j. enpol.2010.01.040

Gwilliam, K. Urban transport in developeding coun- tries. Transport Reviews, 23(2), 197-216, 2003. doi: 10.1080/01441640309893

Halicioglu, F. An econometric study of $\mathrm{CO}_{2}$ emissions, energy consumption, income and foreign trade in Turkey. Energy Policy, 37(3), 1156-1164, 2009. doi: 10.1016/j. enpol.2008.11.012

Hossain, M. S. Panel estimation for $\mathrm{CO}_{2}$ emissions, energy consumption, economic growth, trade openness and urbanization of newly industrialized countries. Energy Policy, 39(11), 6991-6999, 2011. doi: 10.1016/j.enpol.2011.07.042

IEA - Internacional Energy Agency. Energy and Climate Change, 2015. Disponível em: < https://www.iea.org/publications/freepublications/publication/WEO2015SpecialReportonEnergyandClimateChangeExecutiveSummaryPortugueseversion.pdf.> Acesso em: abr. 2018.

IPEA - Instituto de Pesquisa Aplicada. Logística e Transporte no Brasil: uma análise do programa de investimentos 2013-2017 em rodovias e ferrovias, 2016. Disponível em: $<$ http://repositorio.ipea.gov.br/bitstream/11058/7420/1/ RP_Log\%C3\%ADstica_2016.pdf > Acesso em: abr. 2018.

Lean, H. H.; Smyth, R. $\mathrm{CO}_{2}$ emissions, electricity consumption and output in ASEAN. Applied Energy, 87(6), 1858-1864, 2010. doi: 10.1016/j.apenergy.2010.02.003

Lukic, M. S. R. Extrafiscalidade e Regulação da Economia: as mudanças tributárias nos Governos Lula e Dilma. Sequência, 36(71), 197-220, 2015. doi: 10.5007/2177-7055.2015v3 6n71p 197

Menyah, K.; Wolde-Rufael, Y. Energy consumption, pollutant emissions and economic growth in South Africa. Energy Economics, 32(6), 1374-1382, 2010. doi: 10.1016/j. eneco.2010.08.002

Morecroft, J. D. Strategic Modelling and Business Dynamics: a feedback systems approach. Nova Deli: Wiley, 2 ed., 2015.

Naim, M. M.; Towill, D. R. Establishing a Framework for Effective Materials Logistics Management. The International Journal of Logistics Management, 5(1), 81-88, 1994. doi: 10.1108/095740994108

Narayan, P. K.; Smith, R. Energy consuption and real GDP in $\mathrm{G} 7$ countries: new evidences from panel cointegration 
with structural breaks. Energy Economics, 30, 2331 - 2341, 2008. doi: 10.1016/j.eneco.2007.10.006

Niu, S.; Ding, Y. A.; Niu, Y. A.; Li, Y. A.; Luo, G. A. Economic growth, energy conservation and emissions reduction: A comparative analysis based on panel data for 8 Asian-Pacific countries. Energy Policy, 39(4), 2121-2131, 2011. doi: 10.1016/j.enpol.2011.02.003

Observatório do Clima. Sistema de Estimativa de Emissões de Gases de Efeito Estufa (SEEG), 2017. Disponível em $<$ http://www.observatoriodoclima.eco.br/wp-content/ uploads/2017/10/seeg2017presskit_FINAL.pdf > . Acesso em: abr. 2018.

Ong, H. C.; Mahlia, T. M. I.; Masjuki, H. H. A review on energy pattern and policy for transportation sector in Malaysia. Renewable and Sustainable Energy Reviews, 16(1), 532-542, 2012. doi: 10.1016/j.rser.2011.08.019

Ozturk, I.; Acaravci, A. The long-run and causal analysis os energy, growth, opennes and financial development on carbono emissions in Turkey. Energy Economics, 36, 2013, 262-267. doi: 10.1016/j.eneco.2012.08.025

Pao, H.; Tsai, C. $\mathrm{CO}_{2}$ emissions, energy consumption and economic growth in BRIC countries. Energy Policy, 38(12), 7850-7860, 2010. doi: 10.1016/j.enpol.2010.08.045

Pao, H.; Tsai, C. Multivariate Granger causality between $\mathrm{CO} 2$ emissions, energy consumption, FDI (foreign direct investment) and GDP (gross domestic product): Evidence from a panel of BRIC (Brazil, Russian Federation, India, and China) countries. Energy, 36(1), 685-693, 2011. doi: 10.1016/j.energy.2010.09.041

Raiser, M.; Clarke, R.; Procee, P.; Briceno-Garmendia, C. De volta ao planejamento: como preencher a lacuna de infraestrutura no Brasil em tempos de austeridade. Banco Mundial, 2017. Disponível em:http://documents.worldbank. org/curated/pt/237341502458978189/pdf/117392-PORTUGUESE-PorBacktoPlanningFinal.pdf 28. Acesso em: jul. 2018

Richardson, G. Feedback thought in social science and systems theory. Philadelphia: University of Pennsylvania
Press, 1996.

Saboori, B.; Sapri, M.; Baba, M. B. Economic growth, energy consumption and $\mathrm{CO}_{2}$ emissions in OECD (Organization for Economic Co-operation and Development)'s transport sector: A fully modified bi-directional relationship approach. Energy, 66, 150-161, 2014. doi: 10.1016/j. energy.2013.12.048

Sari, R.; Soytas, U. Are global warming and economic growth compatible? Evidence from five OPEC countries? Applied Energy, 86(10), 1887-1893, 2009. doi: 10.1016/j.apenergy.2008.12.007

Shepherd, S. P. A review of system dynamics models applied in transportation. Transportmetrica B: Transport Dynamics, 2(2), 83-105, 2014. doi: 10.1080/21680566.2014.916236

Snieska, V.; Simkunaite, I. Socio-economic impact of infrastructure investments. Engineering Economics, 63(4), 2009.

Sterman, J. D. Business dynamics: systems thinking and modeling for a complex world. Boston: Irwin/McGraw-Hill, 2000 .

Stern, D. I. Energy and economic growth in the USA: a multivariate approach. Energy Economics, 15, 137-150, 1993. doi: 10.1016/0140-9883(93)90033-N

Vershinina, A. A.; Olga, A. Z.; Tatiana, P. M.; Denis, G. P. The formation of indicator framework for effective assessment of investment attractiveness of the region. International Journal of Economics and Financial Issues, 5(3S), 136-141, 2015. Disponível em: http://www.econjournals. com/index.php/ijefi/article/view/1703

Wang, Ss.; Zhou, D.; Zhou, P.; Wang, Qw. $\mathrm{CO}_{2}$ emissions, energy consumption and economic growth in China: a panel data analysis. Energy Policy, 39, 4870-4875, 2011. doi: 10.1016/j.enpol.2011.06.032

Wilbert, M. D.; Serrano, A. L. M.; Gonçalves, R. S.; Alves, L. S. Redução do imposto sobre produtos industrializados e seu efeito sobre a venda de automóveis no Brasil: uma análise do período de 2006 a 2013. Revista Contemporânea de Contabilidade, 11(24), 107-124, 2014. doi: $10.5007 / 2175-8069.2014 \mathrm{v} 11 \mathrm{n} 24 \mathrm{p} 107$ 